\title{
COMPARATIVE STUDY OF TEMPERATURE BASED EQUATIONS IN ESTIMATION OF POTENTIAL EVAPORATION FOR ANGUNA- KOLAPELESSA IN THE ARID ZONE OF SOUTHERN SRI LANKA
}

\author{
K. D. N. WEERASINGHE \\ Department of Agronomy, Faculty of Agriculture, University of Rubuna, \\ Matara, Sri Lanka.
}

(Date of receipt : 23.04.85)

(Date of acceptance : 23.07.86)

\begin{abstract}
The methods of Penman, Thornthwite, Linacre, and Ivanov were used to estimate potential evaporation for Angunakolapelessa. The estimates were compared with adjusted values of evaporation measured by the Class $A$ evaporation pan. The Ivanov's equation gives reliable estimates of potential evaporation provided that the average wind speed of the area is $<9 \mathrm{~km} / \mathrm{hr}$. The regression analysis indicated that in Angunakolapelessa where the fluctuation of air temperature in the annual cycle is low, the potential evaporation has a more significant relationship with relative humidity. A regression equation is proposed to measure the potential evaporation of the area including the relative humidity as the only climatic variable.
\end{abstract}

\section{Introduction}

Several dozens of empirical or semi-empirical temperature based methods have been applied with considerable success in various parts of the world for estimation of evapotranspiration. ${ }^{2,3}$ All these methods work on the assumption that abundant water is available for free evaporation.

In the early stages, N.N. Ivanov ${ }^{1}$ used the relationship between temperature and relative humidity to estimate the potential evaporation (PE). Blaney and Criddle ${ }^{4}$ related PE to daytime hours and the mean monthly temperature; Thornthwite ${ }^{6}$ has related $\mathrm{PE}$ to air temperature and the monthly heat index.

A much more complex effort demanding more meteorological data was suggested by Penman. 4,5 The equation which he developed links PE rate to the net flux of radiant energy at the surface and to the effective ventilation of the surface by air in motion over it. The Penman's equation is most widely used in hydrology today. A simplified Penman equation was suggested by Edward T. Linacre ${ }^{3}$ relating PE to temperature, dewpoint and altitude. 
Since all these equations have their limitations of application for a given location, work on the accuracy of estimation should be conducted in each hydrological region. Although the Penman approach is well established, investigations are still being conducted on the computation of Penman's potential estimates for tropical countries. ${ }^{2}$ The aim of the present research is to evaluate the impact of meteorological factors on actual evaporation and to compare values of potential evaporation derived using Penman's with those of simpler equations and actual evaporation measured by the class $\mathrm{A}$ Evaporation Pan.

\section{Materials and Methods}

The monthly meteorological data measured by the Angunakolapelessa Meteostation for 6 consecutive years (1977-1982) were used for the study.

In order to determine the individual effects of air temperature, wind speed and relative humidity of the location on actual evapotranspiration, a correlation analysis was conducted. The combined effect of each meteorological factor on potential evaporation was calculated by the multiple regression method.

The estimated values were correlated with pan evaporation data to select the most suitable method for the location. Data were analysed in the Computer Centre, Climatic Research Unit, University of East Anglia, U.K.

\section{Results and Discussion}

The rainfall distribution of the Angunakolapelessa area follows a well expressed bimodal pattern. The mean annual rainfall during 1977-1982 was $1091 \mathrm{~mm}$. On the basis of rainfall January-March and July-September are comparatively dry months (Table 1 ). The highest rainfall is in November. January and February are normally associated with drought.

The mean average temperature of the region is $27.5^{\circ} \mathrm{C}$. The lowest temperature $\left(26^{\circ} \mathrm{C}\right)$ is recorded in December-February which is probably associated with the low solar radiation.

The amount of rainfall received in May and November exceeds the amount evaporated by free water surface (Table 1). The average annual climatological constant of the area according to N.N. Ivanov is 0.57. The climate of the area approaches the dry steppe, where agriculture may not be feasible without providing irrigation. Forest belts and soil moisture conservation methods are advisable in order to conserve soil moisture. 


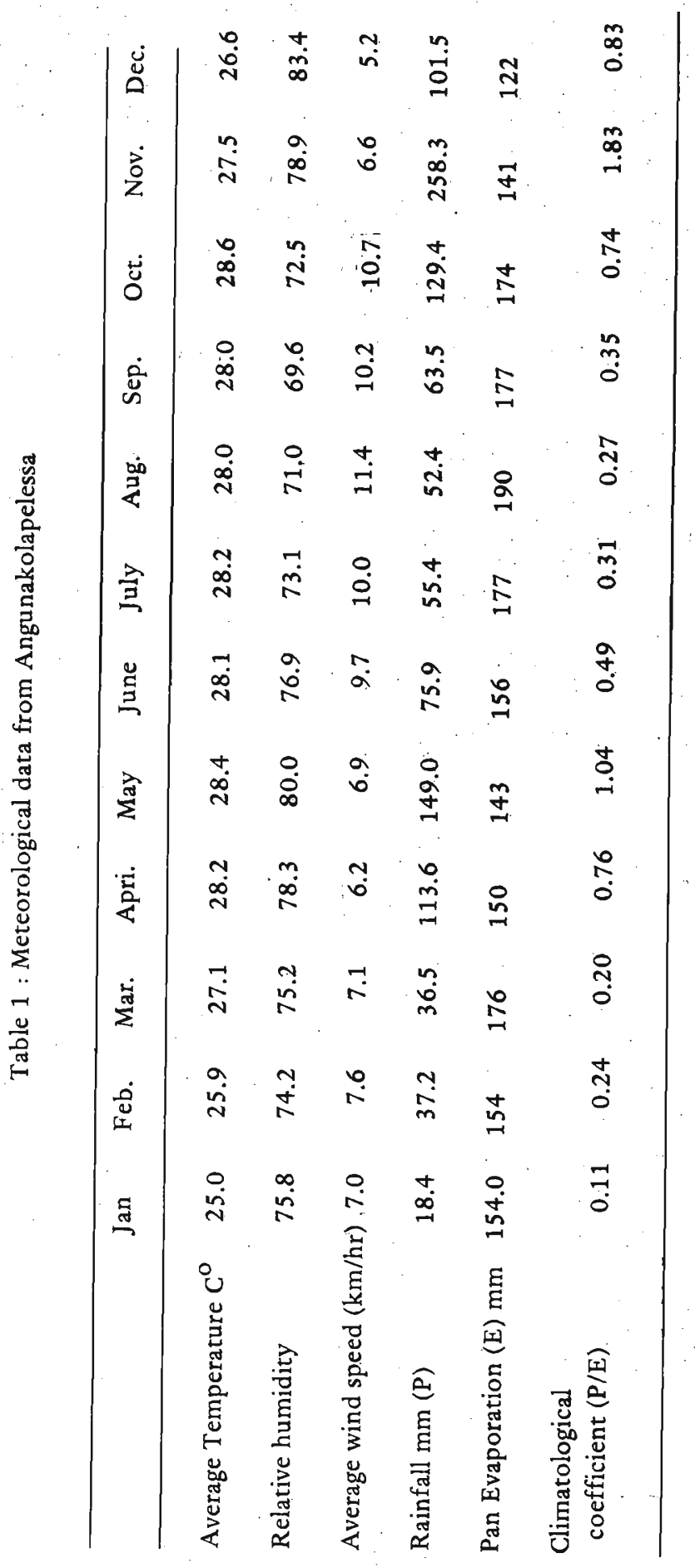


The estimated values of potential evaporation by Linacre, Penmann Thornthwite and Ivanov's methods were significantly larger than the measured Pan Evaporation by about $91.3 \%, 81.2 \%, 37.9 \%$ and $8.9 \%$ respectively and the estimates were significantly differed from the measured Pan Evaporation values.

The monthly estimates of Penman's and Ivanov's values with actual evaporation values is more similar. But the correlation between Penman's and actual values is less pronounced compared to the estimated values by Ivanov's equation (Table 3). Nevertheless it is noteworthy that PE estimated by Ivanov's equation has a significant high correlation with estimated values by Penman's method.

Derivation of actual potential evaporation (Table 2) from evaporation data when the pan coefficient is considered as 0.7 will enable the Ivanov's equation to be used with more confidence. Nevertheless there is a significant difference in computed values by the Ivanov method over the measured values when high winds are prevailing during June-October. This indicates that the Ivanov method gives reliable estimates of potential evaporation on the monthly basis provided that the average wind speed is less than $9 \mathrm{~km} / \mathrm{hr}$.

In Angunakolapelessa where the fluctuation of air temperature in the annual cycle is low the potential evaporation has a more significant relationship with relative humidity (Table 4) than with temperature or other environmental factors.

\section{Discussion}

The actual evaporation values measured by the Class A pan evaporimeter agree with the potential evaporation values calculated by N.N. Ivanov's method. Nevertheless Ivanov's model would operate satisfactorily if the wind speed of the area is low.

The calculated correlation coefficients (Table 4) give an idea of the probable effect of wind and other meteorological factors on the actual evaporation of the area.

The possible regressions of each meteorological factor over the evaporation in different possible combinations are given in Table 5. The analysis of variance of the data indicates that the effect of relative humidity (x3) on evaporation is highly significant whether or not the temperature $(\mathrm{x} 4)$ and wind $(x 2)$ have an effect on it. If relative humidity is assumed to have an effect on evaporation, then the effect of temperature and wind speed is nonsignificant even at the $10 \%$ level. Similarly if relative humidity and temperature have an effect on evaporation then the influence of wind is non- 


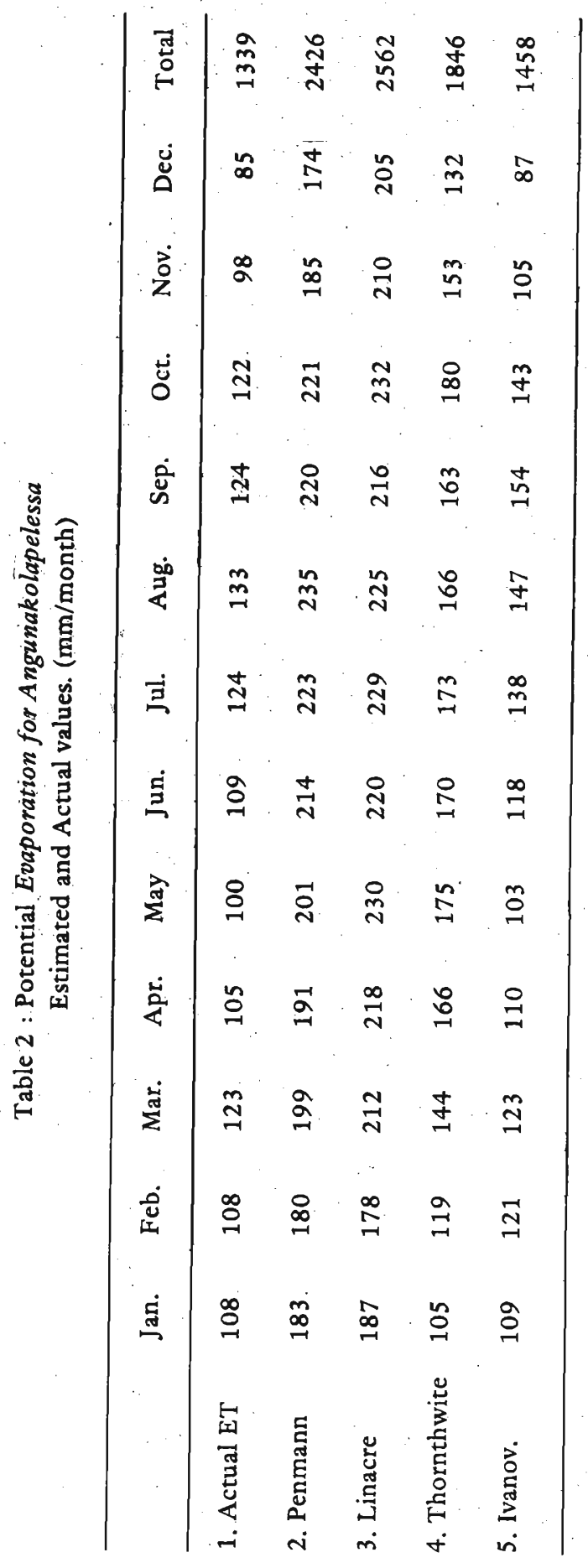




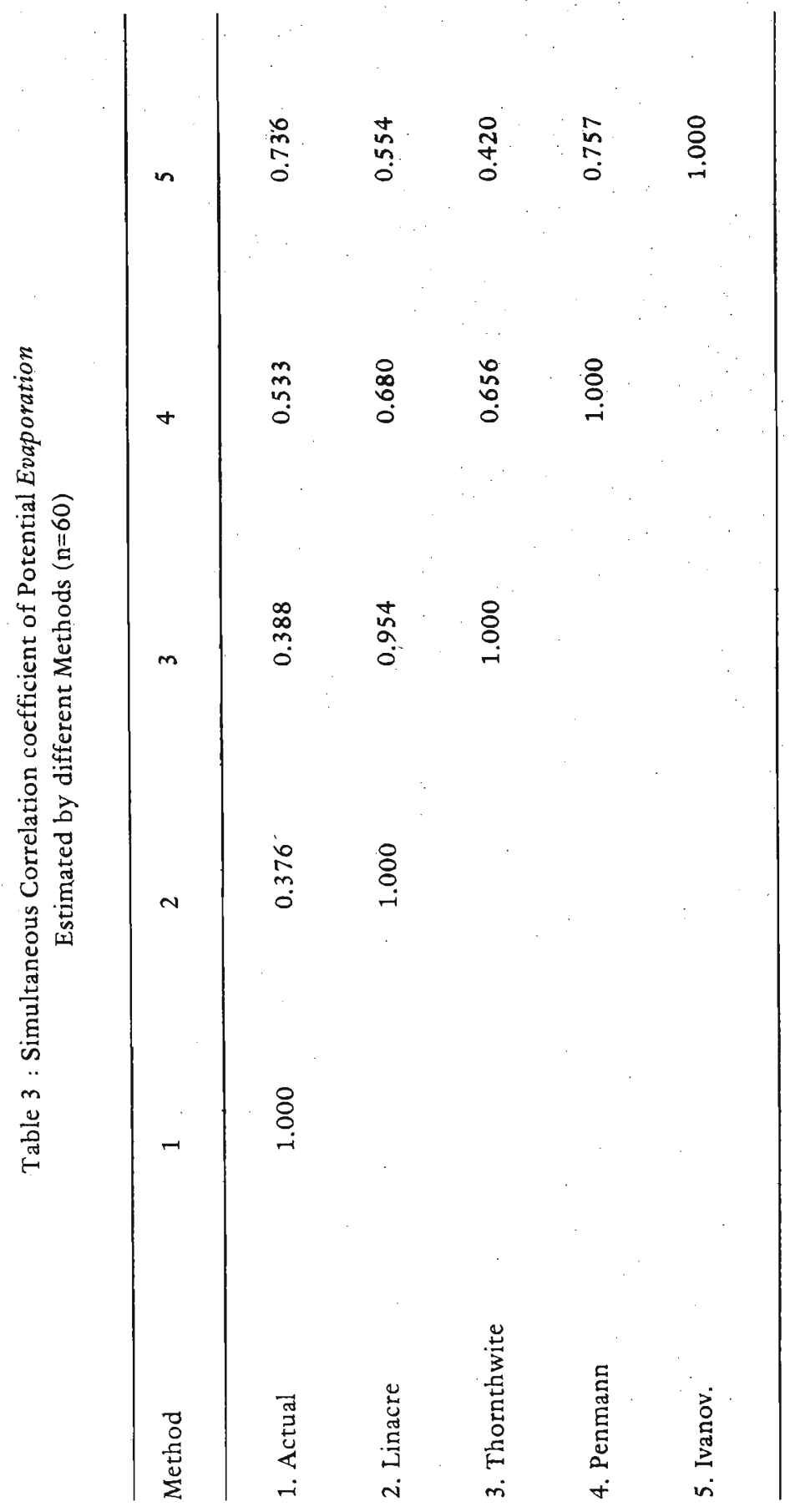


Table 4 : Correlation coefficients between actual Evaporation and Environmental Factors.

\begin{tabular}{lllll}
\hline Meteo Readings & 1 & 2 & 3 & 4 \\
\hline 1. Evaporation & 1.000 & 0.528 & -0.739 & 0.384 \\
2. Wind speed & & 1.000 & -0.735 & 0.448 \\
3. Relative humidity & & & 1.000 & -0.387 \\
4. Air temperature & & & 1.000 \\
\hline
\end{tabular}

Table 5 : Analysis of variance of the different meteorological factors over the evaporation

\begin{tabular}{|c|c|c|c|c|}
\hline S.V. & S.S. & D.F. & M.S. & F. Value \\
\hline Regression of $X_{2} X_{3} x_{4}$ & 14273.3 & 3 & 4745.76 & $23.65^{*}$ \\
\hline $\mathrm{x}_{2} \mathrm{x}_{3}$ ignoring $\mathrm{x}_{4}$ & 13905.3 & 2 & 6952.65 & $34.65^{*}$ \\
\hline$x_{2} x_{4}$ ignoring $x_{3}$ & 7773.8 & 2 & 3886.9 & $19.37^{*}$ \\
\hline$x_{3} x_{4}$ ignoring $X_{2}$ & 14169.4 & 2 & 7084.7 & $35.31^{*}$ \\
\hline$x_{2}$ ignoring $x_{3} x_{4}$ & 7089.3 & 1 & 7089.3 & $35.33^{*}$ \\
\hline $\mathrm{x}_{3}$ ignoring $\mathrm{X}_{2} \mathrm{x}_{4}$ & 13892.3 & 1 & 13892.3 & $69.24^{*}$ \\
\hline$x_{4}$ ignoring $x_{3} x_{2}$ & 3746.61 & 1 & 3746.61 & $18.67^{*}$ \\
\hline $\mathrm{X}_{2}$ assuming $\mathrm{X}_{3}$ ignoring $\mathrm{X}_{4}$ & 13.0 & 1 & 13.0 & 0.064 \\
\hline $\mathrm{X}_{4}$ assuming $\mathrm{X}_{2}$ ignoring $\mathrm{X}_{3}$ & 684.5 & 1 & 684.5 & 3.41 \\
\hline $\mathrm{X}_{2}$ assuming $\mathrm{X}_{4}$ ignoring $\mathrm{X}_{3}$ & 4027.19 & 1 & 4027.19 & $20.07^{*}$ \\
\hline$X_{4}$ assuming $X_{3}$ ignoring $X_{2}$ & 277.1 & 1 & 277.1 & 1.38 \\
\hline$x_{2}, x_{4}$ assuming $x_{3}$ & 345.0 & 2 & 172.5 & 0.85 \\
\hline Error & 11235.7 & 56 & 200.6375 & \\
\hline \multirow[t]{2}{*}{ Total } & 25473 & 59 & & \\
\hline & \multicolumn{3}{|c|}{$\begin{array}{ll}\mathrm{x}_{2} & \text { Average wind speed } \mathrm{Km} / \mathrm{l} \\
\mathrm{X}_{3} & \text { Relative humidity, } \% \\
\mathrm{X}_{1} & \text { Air temperature }\end{array}$} & \\
\hline
\end{tabular}


significant. Therefore it is clearr that the relative humidity alone is sufficient to explain the variation of potential evaporation at the $1 \%$ level.

The regression line with relative humidity alone in the model would read as

$$
\mathrm{y}=346.69-3.1185 \mathrm{x}_{3}\left(\mathrm{x}_{3}=\text { Relative humidity }\right)
$$

This regression line would be a useful tool in estimating potential evaporation for Angunakolapelessa.

\section{Acknowledgements}

The author gratefully acknowledges the assistance of many members of the staff of the Climatic Research Unit, University of East Anglia, U.K. and in particular of Dr. G. Farmer in respect of this paper. Thanks are due also to W.M.O. and U.N.D.P. for the travel grant and Fellowship provided to follow the professional course, "Understanding Climate" during which this work was completed.

Special mention must be made of Miss Indrani Weerasinghe, for her valuable help in the statistical analysis.

\section{References}

1. BESMENOV, A.I., ROSIN, V.A. (1974). Selsko. Hasyast Vennaya Melioratia; Moscow.

2. Institute of Hydrology Research Report 1978-81.

Water use by Tropical crops pp. 69-70.

3. LINACRE, E.T. (1977). A simple formula for estimating evapotranspiration rates in various climates, using temperature data alone. Agric. Meteorology 18: 409-424.

4. PENMAN, H.L. (1963). Vegetation and Hydrology. Technical Communication No. 53. C.A.B. 1963.

5. PENMAN, H.L. (1948). Natural Evaporation from open water, bare soil and grass. Proc. Roy. Soc. Lond. (A) 193 : $120-145$.

6. THORNTHWITE, C.W. (1948). An approach toward a rational classification of climate. Geogrl. Rev. 38: 85-9:4. 